\title{
Influence of Airgap Length on Performance of High Power PM-Assisted Syn-Rel Machines
}

\author{
Tianjie Zou ${ }^{1}$, David Gerada ${ }^{1}$, Adam Walker ${ }^{1}$, Gaurang Vakil ${ }^{1}$, Salvatore La Rocca ${ }^{1}$, Antonino La Rocca ${ }^{1}$, \\ Krzysztof Paciura ${ }^{2}$, Richard Barden ${ }^{2}$, Emil Ernest ${ }^{2}$, Shaohong Zhu ${ }^{2}$, Naila Qayyum², Alastair McQueen ${ }^{2}$, \\ Anuvav Bardalai ${ }^{1}$, R. M. Ram Kumar ${ }^{1}$, Alessandro Marfoli ${ }^{1}$, and Chris Gerada ${ }^{1}$ \\ ${ }^{1}$ Power Electronics, Machines and Control (PEMC) Group, University of Nottingham, NG7 2RD, Nottingham, UK \\ ${ }^{2}$ Cummins Corporate R\&T, PE15WS, Peterborough, UK \\ Email: Tianjie.Zou@nottingham.ac.uk; David.Gerada@nottingham.ac.uk; \\ Chris.Gerada@nottingham.ac.uk
}

\begin{abstract}
In recent years, synchronous reluctance (Syn-Rel) machines are research hotspots in variable speed motor drives due to their robust rotor structure and wide constant power speed range (CPSR). More practically, when kVA limitation is considered, embedded permanent magnets (PMs) have been widely adopted in Syn-Rel rotors to further increase power density as well as power factor. In this paper, the authors have investigated the potential of PM-assisted Syn-Rel machine to be the next generation electrical propulsion motor topology for automotive application, with special attention put on a key geometric parameter, i.e., airgap length. In MTPA region, the influence of airgap length on different torque components has been analyzed in detail based on the frozen permeability method. In field weakening region, the variation trend of several key performance such as peak power, iron loss and torque ripple have been investigated along with airgap length. It is found that with specifically high level of electric and magnetic loading, there exists optimal value of airgap length to achieve high power density based on specific cooling and KVA limitation. Numerical FEA and experimental tests are associated to validate the conclusions.
\end{abstract}

Index Terms-airgap length, synchronous reluctance machine, high speed machine, $\mathrm{NdFeB}$ magnets, high power density.

\section{INTRODUCTION}

During the last decades, synchronous reluctance (Syn-Rel) machines have drawn ever increasing attentions in variable speed traction application, mainly due to their PM-free characteristic, high rotor robustness and superior constant power capability [1-5]. Meanwhile, researchers have realized that permanent magnets (PMs) are still essential for this machine type to form PM-assisted Syn-Rel machine with higher power factor, when practical kVA limitation is considered [6-7]. Moreover, if high power density is further pursued, which is actually the trend in electrical propulsion market, high energy density magnets such as $\mathrm{NdFeB}$ are still preferred. Typical examples are traction machines in Toyota Prius and BMW i3 [8], which basically adopt hybrid topologies of conventional interior-PM (IPM) and Syn-Rel machines, with strong $\mathrm{NdFeB}$ magnets embedded into the rotors. Prior to this paper work, the authors have been involved in investigating the potential of typical PM-assisted Syn-Rel machines, to achieve superior power density compared with existing motor products in market. As shown in Fig. 1, the target has been set to $3.5 \mathrm{~kW} / \mathrm{kg}$ and $12 \mathrm{~kW} / \mathrm{L}$.

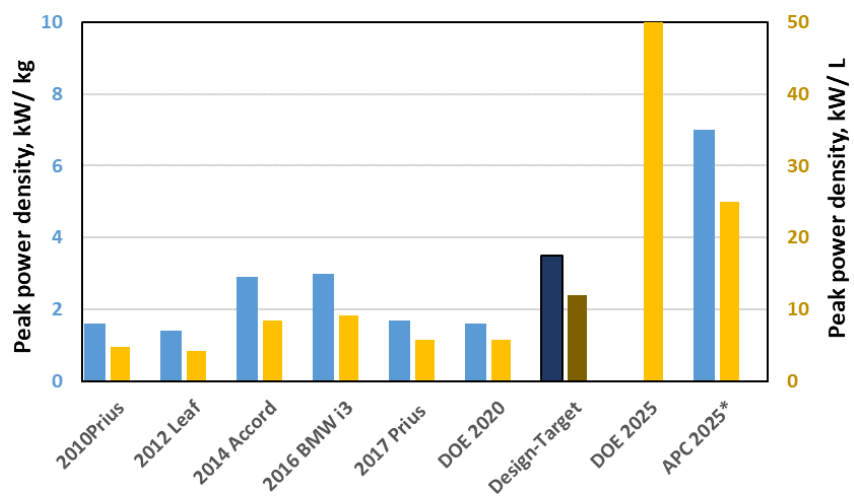

Fig. 1. Peak power density of EV/HEV motors and future roadmaps [8].

Based on the research work, this paper will focus on the influence of airgap length on machine performance. There are mainly two reasons that the "old-fashioned" design parameter is brought back to stage. As illustrated in Fig. 1, both DoE 2025 report from the Department of Energy in US (peak value) and the APC (Advanced Propulsion Centre) Roadmap 2025 in UK (continuous value) have targeted on significant increase in machine's power density for EV/HEV within next 5 years. Hence, both "ultra-high speed" and "ultra-high torque density" will be the trend of next generation design. "Ultra-high speed" may bring the possibility of adopting extra rotor sleeve with prestress for Syn-Rel machines (just like what has been done for high speed surface-mounted PM machines), and this will increase electromagnetic airgap length. On the other hand, "ultra-high torque density" makes preferred airgap as small as possible, since it is widely accepted that reluctance torque will reduce along with airgap. Hence, it is necessary to reevaluate airgap length as the most essential design parameter that would influence comprehensive performance of PM-assisted Syn-Rel machines. 


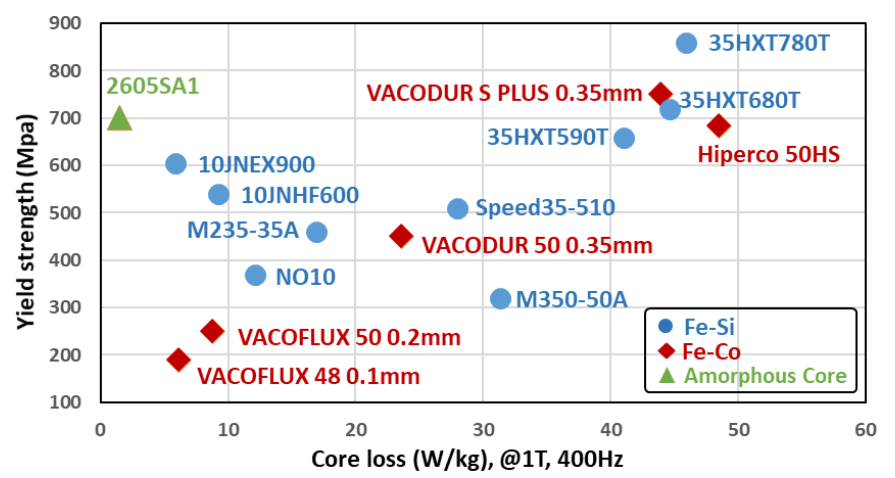

Fig. 2. Core losses and mechanical strength of typical electrical steels [9]

It is widely accepted that the machine design towards high power density is highly dependent on the effective material properties. In this paper, high performance electrical steel 10JNEX900 and 35HXT780T are adopted for the stator and rotor core, respectively, as shown in Fig. 2 [9]. 10JNEX900 is the state of art $\mathrm{Si}-\mathrm{Fe}$ steel with lowest core loss density, while $35 \mathrm{HXT780T}$ is with high yield strength of $840 \mathrm{Mpa}$ and thus suitable to be the material for high speed rotor lamination. The targeted power and torque-speed curve is given in Fig. 3, with more detailed performance requirements and design limitation listed in Table I. It can be seen that the power rating of this machine is significantly higher than typical EV traction motors, as the authors also aim to explore the feasibility of high performance "single motor power train".

The whole machine design process is a multi-physics problem with limited boundary on electromagnetic (EM), thermal and mechanical aspects. For example, Fig. 4 gives a global parametric rotor topology from Jmag Designer for EM and mechanical combined design. The design platform is established using ModeFrontier and Jmag Designer. Meanwhile, this paper is organized as follows: Section II will be focused on discussion of the influence of airgap length on torque performance in MTPA region. Section III will be devoted to machine performance variation along with airgap length in field weakening region. Further, the multi-physics design process will be discussed in Section IV. Afterwards, the experimental setup and some test results will be given in Section V. Finally, the conclusion and suggestion based on the airgap length analysis will be summarized in Section VI.

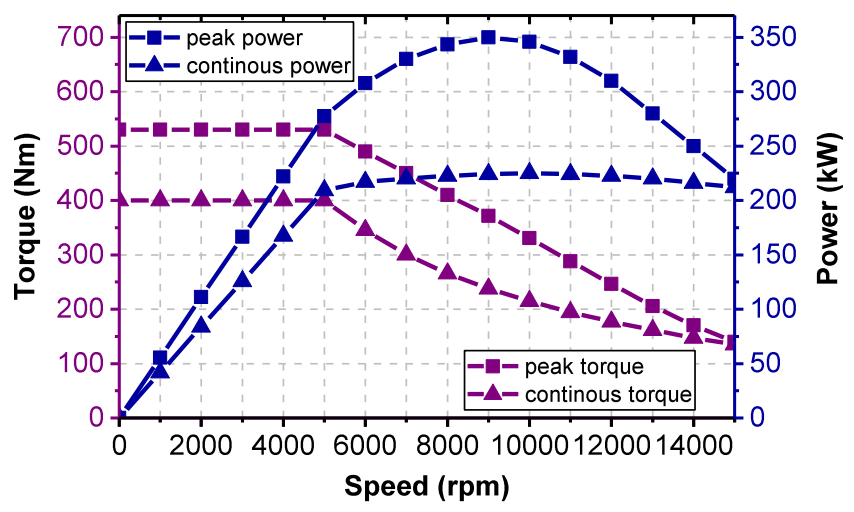

Fig. 3. Targeted torque/ power rating vs. speed for the machine design.
TABLE I

Performance requirements and design limitation

\begin{tabular}{cc}
\hline \hline Item & Value \\
\hline Max. diameter/ length, mm & 350 \\
Max. active mass, kg & 60 \\
Max. non-active mass, kg & 40 \\
Max. inertia, & 0.4 \\
Peak power (30s), kW & 350 \\
Continuous power, $\mathrm{kW}$ & 225 \\
Peak power density, $\mathrm{kW} / \mathrm{kg}$ & $>=3.5$ \\
Peak power density, $\mathrm{kW} / \mathrm{L}$ & $>=12$ \\
\hline \hline
\end{tabular}

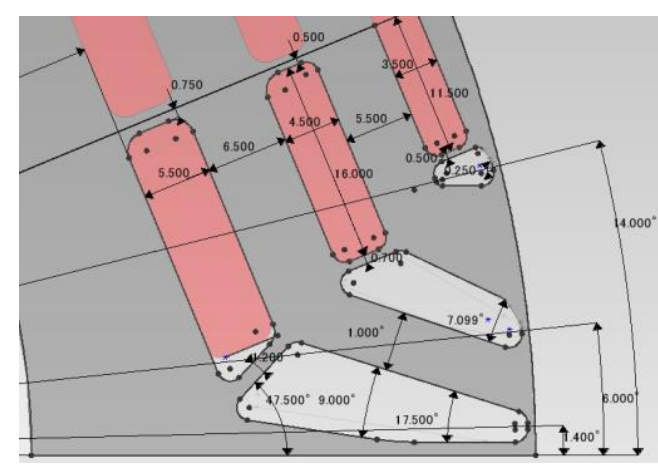

Fig. 4. Basic global parametric rotor topology in Jmag.

\section{INFLUENCE OF AIRGAP LENGTH IN MTPA REGION}

Prior to the discussion in this section, it should be noted that the machine has gone through EM optimization based on different values of airgap length for a fair comparison. In each case, the PM flux linkage and winding inductance have been carefully designed so that the machine falls into "the 2 nd or 3rd type" capability curves according to [10]. That is to say, the machine's characteristic current is no less than rated value under both continuous and peak operation. This can guarantee that the peak power is obtained in deep field weakening region as required in Fig. 3. However, due to space limitation this paper will not show all corresponding results. Instead, only one optimized case (airgap $=1.0 \mathrm{~mm}$ ) is presented. Based on this design, airgap length is then changed while other parameters keep the same. This will also give convincing results of how airgap length can influence machine performance.

Fig. 5(a) shows flux density distribution of the optimized machine fed with pure sinusoidal current under continuous MTPA operation. It is a 72-slot, 8-pole PM-assisted Syn-Rel machine with typical 3-layer barriers in the rotor. N42UH $\mathrm{NdFeB}$ magnets are embedded into central barriers. The current loading under continuous and peak operation are around $800 \mathrm{~A} / \mathrm{cm}$ and $1200 \mathrm{~A} / \mathrm{cm}$, respectively. It can be seen that with high electromagnetic loading, the rotor core is partly saturated especially in its $d$-axis (dq-axis reference frame used for general IPM machines) flux path. In order to separate the influence of airgap length on different torque components, frozen permeability method [8] is used, as shown in Fig. 5(b) and (c). With cross-coupling saturation considered, the mathematical model of the machine is written as Eqn. (1)-(3), while all the four torque components are expressed in Eqn. (4)(7). Both PM torque and reluctance torque contain conventional and cross coupling components as shown in Eqn. (8) and (9). 


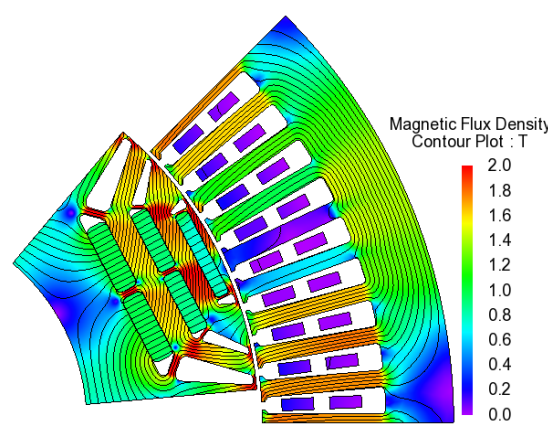

(a) conventional non-linear FEA

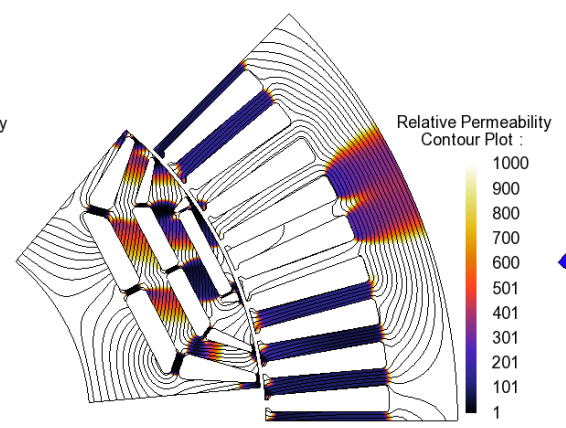

(b) obtained permeability distribution

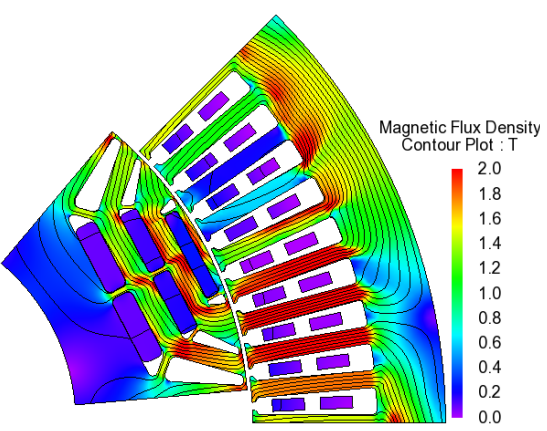

(c) single MMF source based FEA

Fig. 5. Example of adopting frozen permeability method in FEA.

$$
\begin{gathered}
\psi_{P M}=\left(\psi_{P M d}, \psi_{P M q}\right) \\
\psi_{I d}=L_{d} I_{d}, \quad L_{d}=\left(L_{d d}, L_{q d}\right) \\
\psi_{I q}=L_{q} I_{q} \quad L_{q}=\left(L_{d q}, L_{q q}\right) \\
T_{P M-M a i n}=p \psi_{P M d} I_{q} \\
T_{P M-C r o s s}=-p \psi_{P M q} I_{d} \\
T_{R \mathrm{e} l-M a i n}=p\left(L_{d d}-L_{q q}\right) I_{d} I_{q} \\
T_{R \mathrm{e} l-\text { Cross }}=p\left(L_{d q} I_{q}{ }^{2}-L_{q d} I_{d}{ }^{2}\right) \\
T_{P M}=T_{P M-\text { Main }}+T_{P M-\text { Cross }} \\
T_{R \mathrm{e} l}=T_{R \mathrm{e} l-\text { Main }}+T_{R \mathrm{e} l-\text { Cross }} \\
T_{\text {Total }}=T_{P M}+T_{R \mathrm{e} l}
\end{gathered}
$$

In Eqn. (1-10), $\Psi_{P M}$ is the PM flux linkage with both $d$ - and $q$-axis components due to the cross coupling saturation. $\Psi_{I d}$ and $\Psi_{I q}$ are flux linkage induced by $d$ - and $q$-axis current $I_{d}$ and $I_{q}$, respectively. The inductances $L_{d}$ and $L_{q}$ which corresponds to armature reaction from $I_{d}$ and $I_{q}$ contain both self and mutual components. The PM torque $T_{P M}$ related to PM flux linkage consists of two components, i.e., $T_{P M}$ - Main and $T_{P M}$ - Cross. Meanwhile, The reluctance torque related to rotor anisotropy also corresponds to the main part $T_{R e l-M a i n}$ and cross coupling part $T_{R e l-C r o s s}$.

It should be noted that the frozen permeability method are only effective in calculating average value of these torque components. According to the process shown in Fig. 6 [11], all the flux linkage and inductance values can be obtained for torque calculation. Fig. 7 shows the variation of each torque component along with phase advance angle. The sum of these torque components match very well (error $<0.1 \%$ ) with the total torque directly from FEA, which validates the effectiveness of this method.

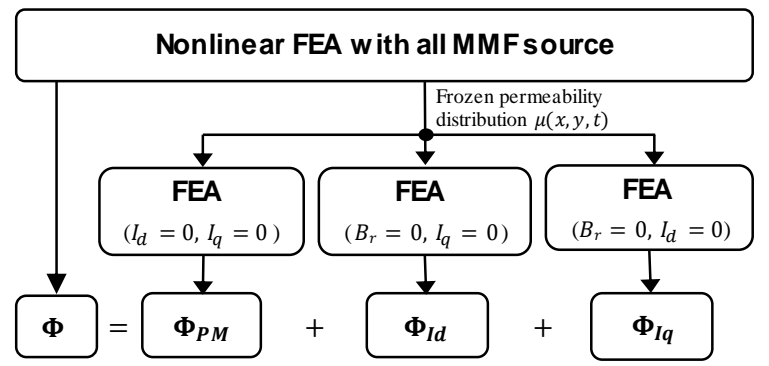

Fig. 6. Decomposition of mathematical model with frozen permeability [11].

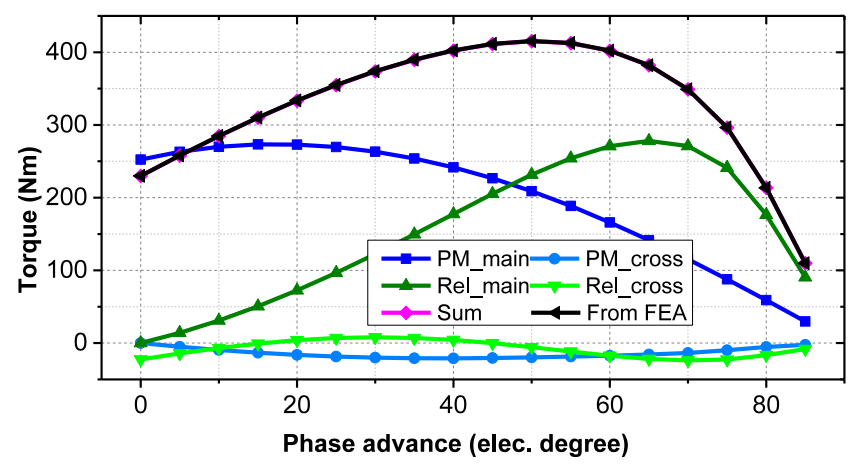

Fig.7. Variation of different torque components with phase advance.

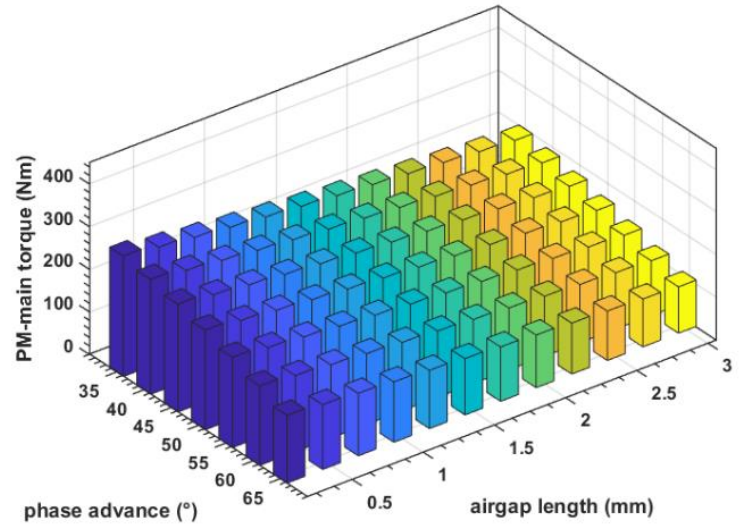

(a). Main PM torque components.

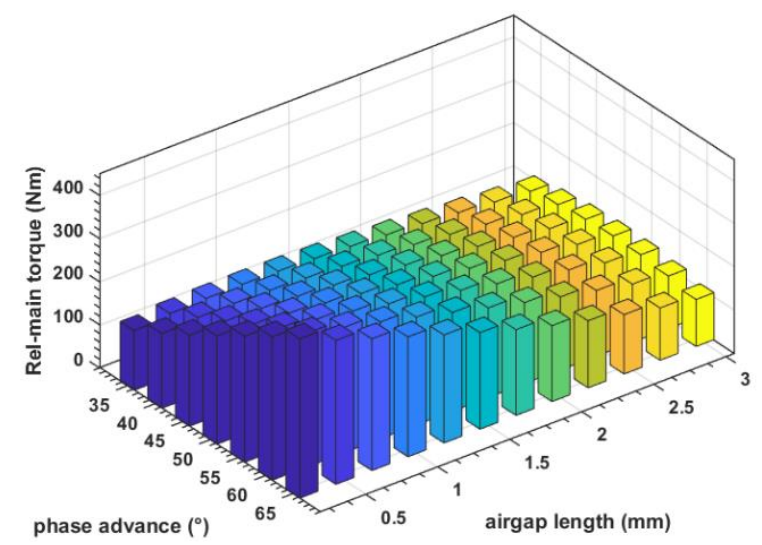

(b). Main reluctance torque components.

Fig. 8. Variation of main torque components along with phase advance and airgap length. 
Fig. 8(a)-(b) shows the influence of airgap length on the main PM and reluctance torque of the machine fed with rated current in continuous operation. First, it can be clearly seen that for each specific phase advance angle, both torque components reduce along with airgap length. For example, with phase advance of $50^{\circ}$, there are $17.8 \%$ and $25.4 \%$ reduction of the main PM and reluctance torque respectively, when the airgap is increased from $0.5 \mathrm{~mm}$ to $2.0 \mathrm{~mm}$. This phenomenon agrees well with basic machine design law, as higher airgap length always corresponds to reduced PM flux linkage as well as winding inductance. It should be noted that the main PM torque is less reduced compared with that of the main reluctance torque. According to Eqn. (4) and (6), this is because $\Psi_{P M}$ is less susceptible compared with $\left(L_{q q}-L_{d d}\right)$, as the magnetic saturation is alleviated with larger airgap.

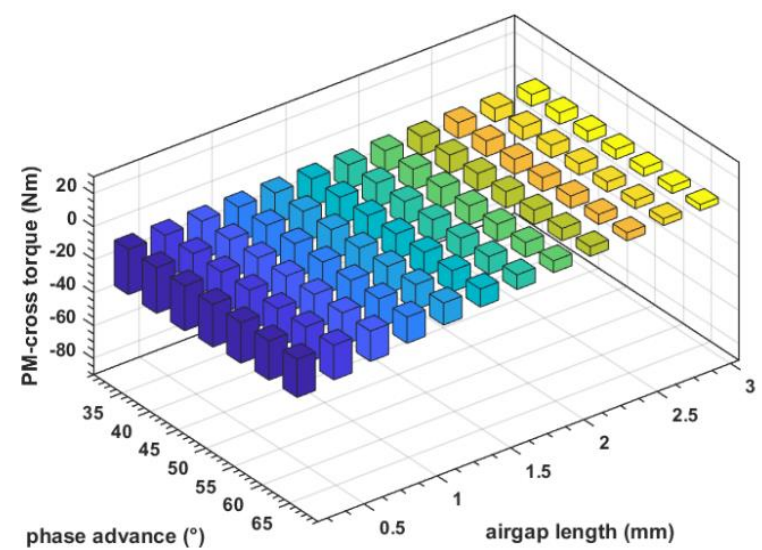

(a). PM torque components (all negative) due to cross coupling saturation.

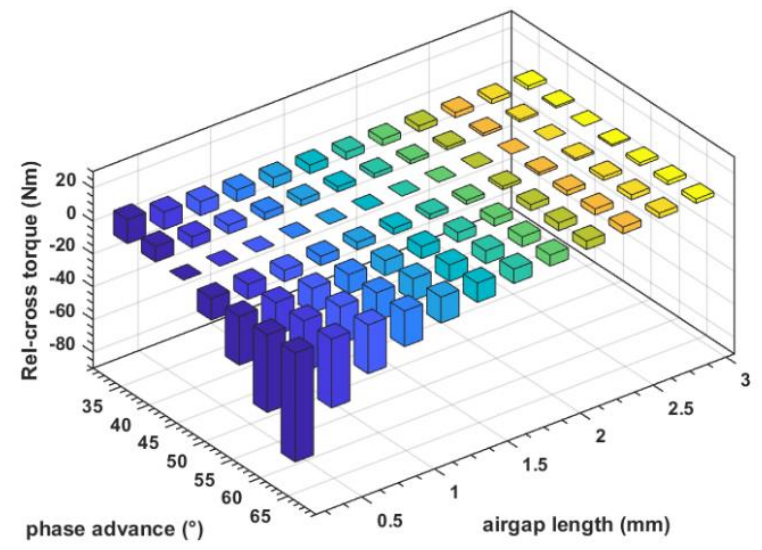

(b). Reluctance torque components (negative in MTPA region).

Fig. 9. Variation of cross coupling torque components along with phase advance and airgap length.

However, the high magnetic and electric loading for high power density target will lead to non-negligible cross coupling saturation. This saturation will then introduce calibration of magnetic pole axis. Hence, there will be additional PM torque produced by $d$-axis current, as well as additional reluctance torque due to mutual inductance between $d$ - and q-axis. In MTPA region, both of these two torque components would be negative and lead to total torque reduction, as can be seen in Fig. 9. With cross coupling considered, the real PM and reluctance torque reduction when airgap changes from $0.5 \mathrm{~mm}$ to $2.0 \mathrm{~mm}$ while phase advance angle remains $50^{\circ}$, is dropped to $13.5 \%$ and $23.2 \%$, respectively. The total torque variation is shown in Fig. 10. Correspondingly, The total torque reduction is $19.0 \%$, in which $5.0 \%$ drop happens from $0.5 \mathrm{~mm}$ to $1.0 \mathrm{~mm}$ airgap reduction, and $14.8 \%$ drop happens from $1.0 \mathrm{~mm}$ to $2.0 \mathrm{~mm}$ airgap reduction.

As a summary for the discussion above, with high electromagnetic loading applied to the PM-assisted Syn-Rel machine, the torque performance will not be as significantly deteriorated as assumed when airgap increases. There are two reasons for this phenomenon. One is, the overall saturation level of the machine is alleviated with larger airgap, so the main PM torque component doesn't drop. The other reason is that with very small airgap, the cross-coupling saturation leads to deviation of magnetic pole axis, and thus producing extra negative torque components which offsets the main torque.

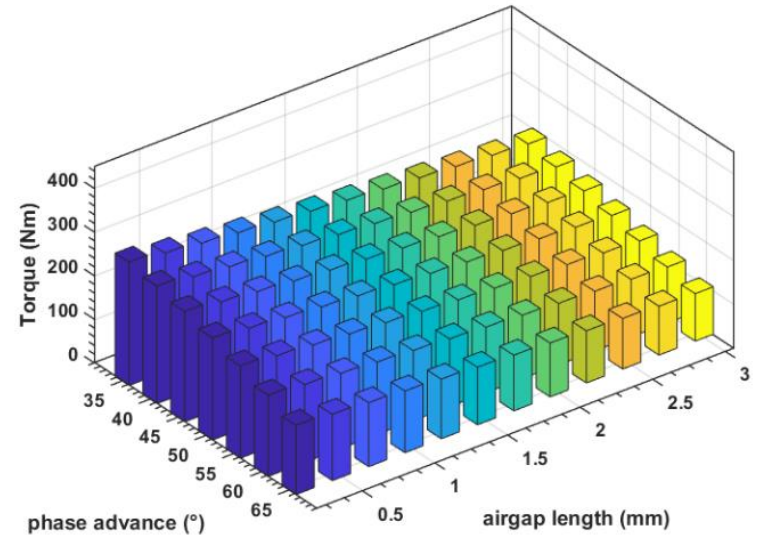

Fig. 10. Variation of total average torque along with phase advance and airgap length.

Meanwhile, the airgap length variation will also influence the optimal phase advance angle to maximize output torque. Take the designed machine as a specific example, the suitable phase advance angle reduces from $55^{\circ}$ to $35^{\circ}$ with airgap increasing from $0.25 \mathrm{~mm}$ to $3.0 \mathrm{~mm}$, as shown in Fig. 11. If different phase advance angle is respectively selected to achieve MTPA for each case of airgap length, it is interesting to find that the corresponding PM torque component doesn't show the trend of reduction at all. This is because more q-axis current is applied for MTPA when airgap increases. Hence, the total torque reduction is basically only introduced by reluctance component.

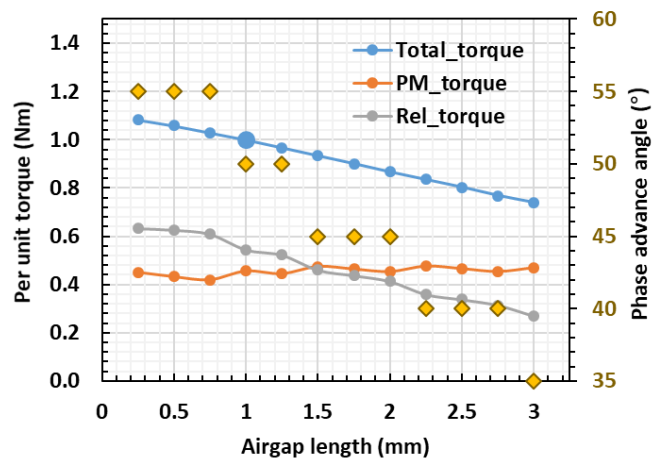

Fig. 11. Influence of airgap length on torque components and optimal phase advance angle. 
III.

\section{INFLUENCE OF AIRGAP LENGTH IN FIELD WEAKENING} REGION

This section will be focused on discussion of how airgap length can affect machine performance when kVA limitation is considered. As introduced, the machine has been designed with characteristic current very close to rated current. Hence, CPSR can be achieved in the whole high speed field weakening region. This is achieved by carefully optimizing machine topology as well as selecting suitable turns in series per phase for windings. For the designed machine, the kVA margin is fixed at $~ 35 \%$ ( maximum power $/ \mathrm{kVA}$ capability $=0.65$ ) for both continuous and peak operation due to specific inverter configuration. In the following analysis, the airgap length will be the only variable, while all the other design parameters have already been optimized based on the airgap $=1.0 \mathrm{~mm}$ case. As explained this is not $100 \%$ reasonable comparison, but can still give intuitive insight on how airgap length can influence machine performance.

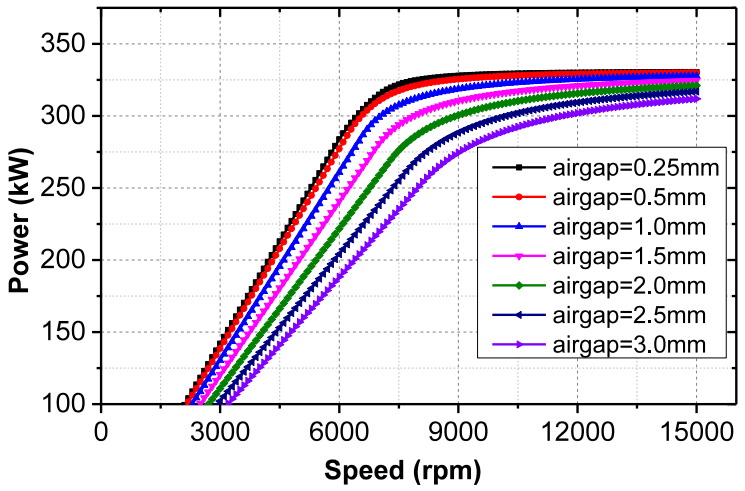

Fig. 12. Power-speed curves based on simplified dq-axis inductance matrix.

In deep field weakening region, the magnetic saturation level of the designed machine is much lower than that of MTPA region. Hence, the cross coupling of both PM flux linkage and $d q$-axis inductance can be neglected. Then, power-speed curve of the machine is analytically derived based on its simplified mathematical model. With the increase of airgap length, both PM flux linkage and d-axis inductance will reduce, and thus affecting the value of characteristic current. Meanwhile, the saliency ratio which also affects maximum power, will also change along with airgap length. Due to space limitation, this paper will not focus on analytical explanation and corresponding discussion. Based on analytical equations, Fig. 12 gives the comparison results of power-speed curves under continuously rated current while with different airgap length. It can be seen that maximum power only slight drops along with increase of airgap length (1.7\% drop from $0.25 \mathrm{~mm}$ to $1.5 \mathrm{~mm}$, $3.9 \%$ drop from $1.5 \mathrm{~mm}$ to $3.0 \mathrm{~mm}$ ).

However, it should be noted that only fundamental voltage and average values of $d q$-axis inductance are considered in field weakening derivation as shown in Fig. 10. With strong armature reaction, there are rich harmonics of inductance with higher orders. These inductance harmonics will produce considerable flux linkage and voltage harmonics, which cannot be simply "weakened" by injecting $d$-axis current and will deteriorate field weakening performance. That is to say, further lower fundamental voltage has to be produced by putting more demagnetizing current, and output power will therefore be reduced. Fig. 13 explains this situation. In practical FEA with all inductance harmonics considered, the achievable maximum power drops significantly with smaller airgap length. With $0.25 \mathrm{~mm}$ and $0.5 \mathrm{~mm}$ airgap, it is even impossible to restrict line voltage to be within DC bus because the harmonic voltage amplitude is too high. Hence, the practical maximum power under fixed kVA will first increase and then reduce along with airgap length. This special phenomenon is introduced by high electromagnetic loading applied to the machine targeting on high power density.

Besides, small airgap may also bring problems of higher iron loss and increased torque ripple in high speed region, as shown in Fig. 14. It should be specially emphasized that cooling of the rotor is quite challenging for high speed EV motors. Hence, It is beneficial to reduce the rotor loss in the EM design stage as much as possible. Based on this consideration, too small airgap needs to be avoided, as the rotor iron loss would be too high to be reduced by optimizing other design parameters. For the specific design with maximum speed operation, the stator and rotor iron loss are reduced significantly by $55 \%$ and $70 \%$ with airgap changing from $0.5 \mathrm{~mm}$ to $1.0 \mathrm{~mm}$. Same conclusion also works for the torque ripple. Fig. 15 further illustrates the rotor iron loss distribution from FEA, which clearly reflects much higher iron loss density induced by stronger armature reaction with small airgap.

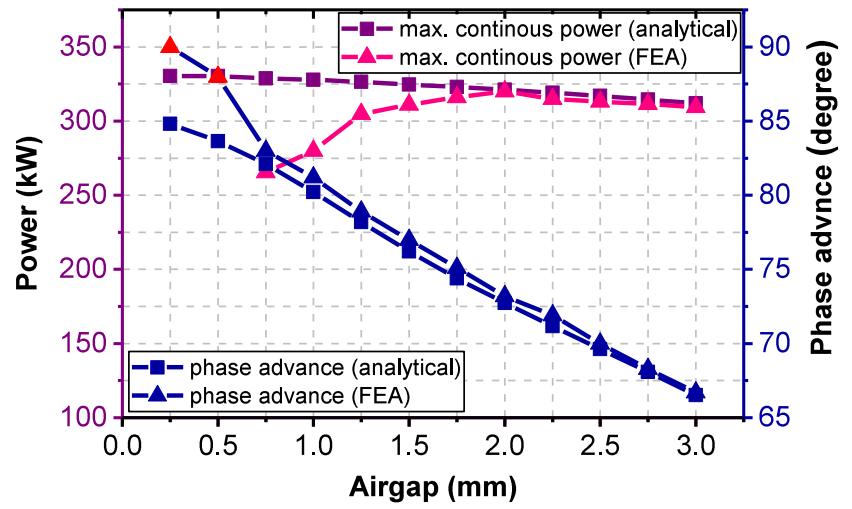

Fig. 13. Comparison of field weakening based on constant and practical $d q$-axis inductance.

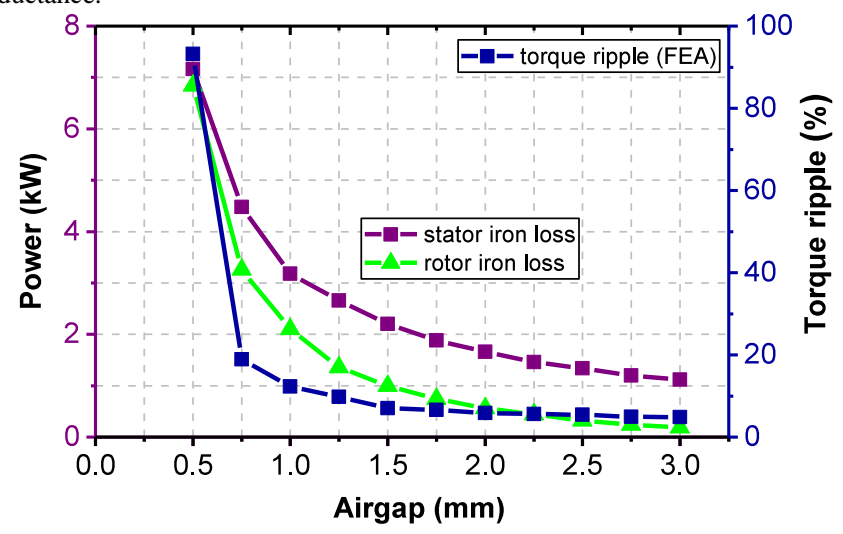

Fig. 14. Influence of airgap length on iron loss and torque ripple in field weakening region. 


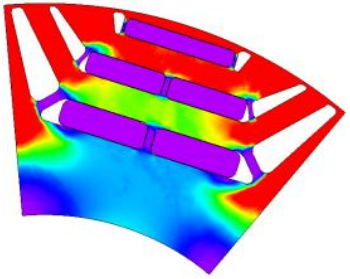

(a) airgap $=0.5 \mathrm{~mm}$

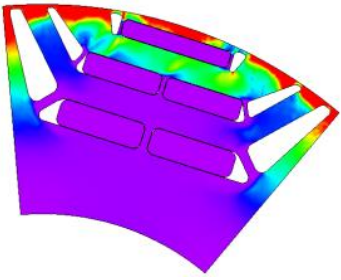

(c) airgap $=1.5 \mathrm{~mm}$

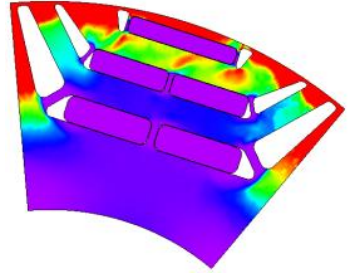

(b) airgap $=1.0 \mathrm{~mm}$

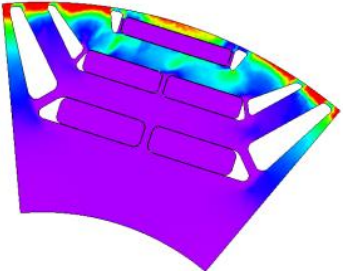

(d) airgap $=2.0 \mathrm{~mm}$ $\begin{array}{lllllllllll}0 & 1 & 2 & 3 & 4 & 5 & 6 & 7 & 8 & 9 & 10^{*} 10^{5} \mathrm{~W} / \mathrm{m}^{3}\end{array}$

Fig. 15. Influence of airgap length on rotor iron loss distribution at highest machine rotation speed.

\section{MUlti-PhysiCs DESIGN}

This section gives some design results based on the established optimization platform. Fig. 16 gives the mechanical stress distribution of the rotor with $10 \%$ overspeed. It can be seen that $15 \%$ margin is achieved considering the yield strength of $840 \mathrm{MPa}$. Fig. 17 shows the temperature distribution of the machine under oil spray cooling on end windings and rotor core. It can be seen that the axially middle part of the stator windings is the hot spot, while the highest temperature rise indicates enough safety margin. Due to space limitation this paper will not focus on details of the multi-physics design. Fig. 18 and 19 illustrate the efficiency map obtained from Jmag under continuous and peak operation, while it should be noted the AC copper loss and windage loss are not accounted yet.

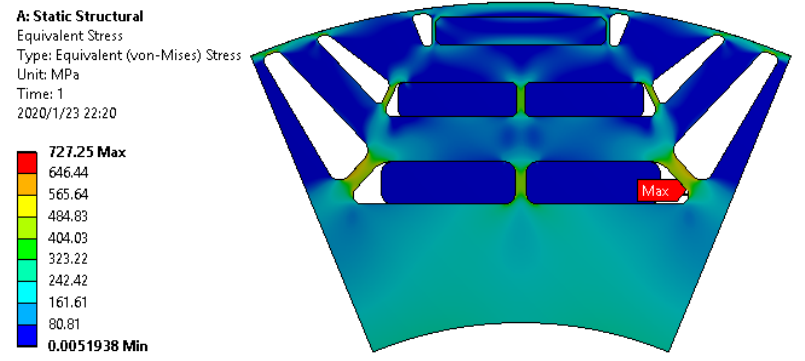

Fig. 16. Mechanical stress distribution of optimized rotor.

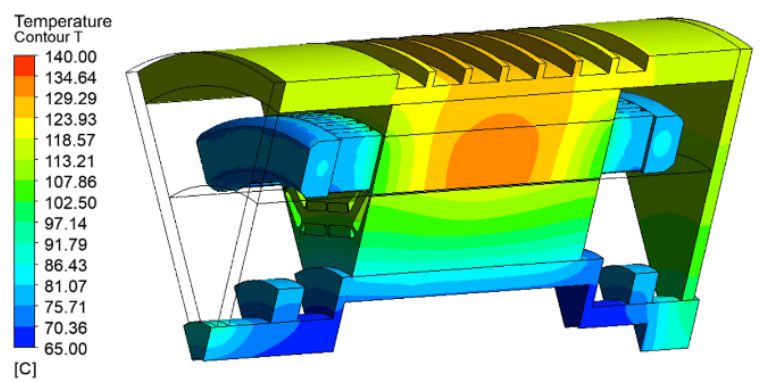

Fig. 17. Temperature distribution of the machine with integrated oil cooling.

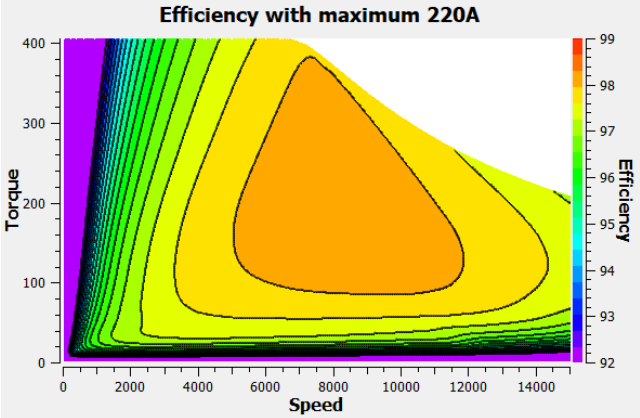

Fig. 18. Torque speed curve for continuous operation based on finalized design.

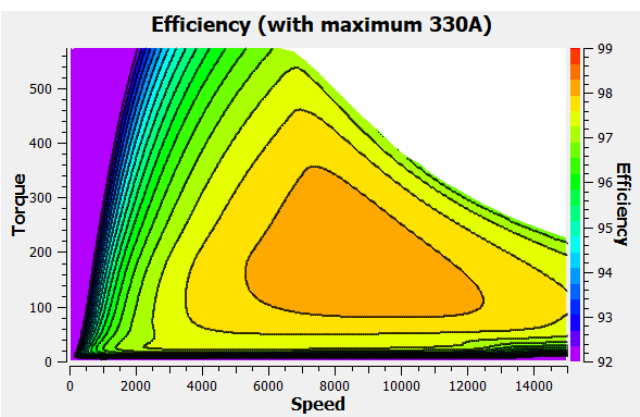

Fig. 19. Torque speed curve for peak operation based on finalized design.

\section{PROTOTYPE AND EXPERIMENTAL SETUP}

Fig. 20 gives the fabricated stator and rotor stacks. V-shape step skewing is applied to the rotor to alleviate both torque ripple and NVH issue. Fig. 21 illustrates the preliminary test bench setup, with power electronics inverter and cooling arrangement integrated. Fig. 21 shows the tested line back-EMF waveforms, which matches very well with simulation results.

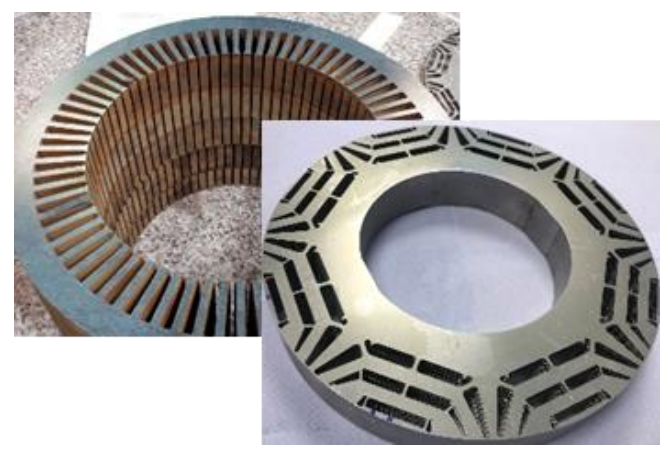

Fig. 20. Stator and rotor core of the prototype machine.

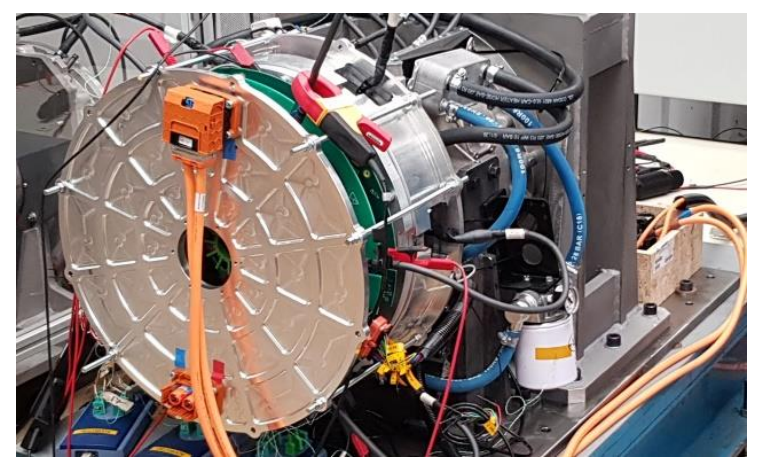

Fig. 21. Stator and rotor core of the prototype machine. 


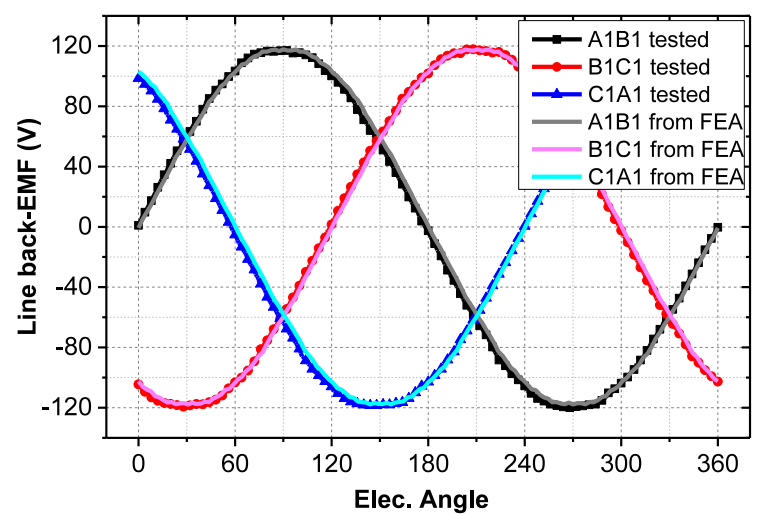

Fig. 21. Comparison of simulated and tested line back-EMF waveforms under 2000rpm.

\section{CONCLUSION}

This paper has investigated the influence of airgap length on performance of high power density PM-assisted Syn-Rel machines in both MTPA and field weakening region. It has been found that the airgap is not a simple "the smaller the better" case which is widely assumed. There exists optimum value of airgap length to achieve overall best machine performance, especially in terms of maximizing power density, reducing iron loss as well as torque ripple.

\section{ACKNOWLEDGEMENT}

The authors would like to thank the Cummins Corporate R\&T in Peterborough, UK, for the support of power train development especially under Covid-19 pandemic. The authors would also like to appreciate the support of JSOL Corporation for providing Jmag-Designer as powerful motor design software. Finally, the research work within this paper is sponsored by the ELITS (Efficient Lightweight Integrated Traction Solution) project under UKRI.

\section{REFERENCES}

[1] A. Vagati, M. Pastorelli, G. Francheschini, and S. Petrache, "Design of low-torque-ripple synchronous reluctance motors," IEEE Trans. Ind. Appl., vol. 34, no. 4, pp. 758-765, Jul./Aug. 1998.

[2] R. Moghaddam and F. Gyllensten, "Novel High-Performance SynRM Design Method: An Easy Approach for A Complicated Rotor Topology," in IEEE Transactions on Industrial Electronics, vol. 61, no. 9, pp. 50585065, Sept. 2014.

[3] M. Barcaro, N. Bianchi and F. Magnussen, "Permanent-Magnet Optimization in Permanent-Magnet-Assisted Synchronous Reluctance Motor for a Wide Constant-Power Speed Range," in IEEE Transactions on Industrial Electronics, vol. 59, no. 6, pp. 2495-2502, June 2012, doi: 10.1109/TIE.2011.2167731.

[4] H. Mahmoud, G. Bacco, M. Degano, N. Bianchi and C. Gerada, "Synchronous Reluctance Motor Iron Losses: Considering Machine Nonlinearity at MTPA, FW, and MTPV Operating Conditions," in IEEE Transactions on Energy Conversion, vol. 33, no. 3, pp. 1402-1410, Sept. 2018, doi: 10.1109/TEC.2018.2811543.

[5] M. D. Nardo, G. L. Calzo, M. Galea and C. Gerada, "Design Optimization of a High-Speed Synchronous Reluctance Machine," in IEEE Transactions on Industry Applications, vol. 54, no. 1, pp. 233-243, Jan.Feb. 2018, doi: 10.1109/TIA.2017.2758759.

[6] N. Bianchi, E. Fornasiero, M. Ferrari and M. Castiello, "Experimental Comparison of PM-Assisted Synchronous Reluctance Motors," in IEEE Transactions on Industry Applications, vol. 52, no. 1, pp. 163-171, Jan.Feb. 2016.

[7] M. Barcaro, N. Bianchi and F. Magnussen, "Permanent-Magnet Optimization in Permanent-Magnet-Assisted Synchronous Reluctance Motor for a Wide Constant-Power Speed Range," in IEEE Transactions on Industrial Electronics, vol. 59, no. 6, pp. 2495-2502, June 2012.

[8] Tim Burress et al., "Electrical Performance, Reliability Analysis, and Characterization," Oak Ridge Nat. Lab., Oak Ridge, TN, USA, Annual Merit Review, June. 2017. [Online]

[9] D. Gerada, A. Mebarki, N. L. Brown, C. Gerada, A. Cavagnino and A. Boglietti, "High-Speed Electrical Machines: Technologies, Trends, and Developments," in IEEE Transactions on Industrial Electronics, vol. 61, no. 6, pp. 2946-2959, June 2014.

[10] N. Bianchi and T.M. Jahns, "Design analysis and control of interior PM synchronous machine", presented at the IEEE Industry Applications Society Annual Meeting, Seattle, USA, October 3rd, 2004. pp 2.14-2.18.

[11] K. Yamazaki and M. Kumagai, "Torque analysis of interior permanentmagnet synchronous motors by considering cross-magnetization: variation in torque components with permanent-magnet configurations," in IEEE Transactions on Industrial Electronics, vol. 61, no. 7, pp. 31923201, July 2014 